\title{
Referral patterns and the referral system for oral surgery care. Part 1: General dental practitioner referral patterns
}

\author{
P. Coulthard, ${ }^{1}$ I. Kazakou, ${ }^{2}$ R. Koron, ${ }^{3}$ and H. V. Worthington, ${ }^{4}$
}

\begin{abstract}
Objective To investigate current GDP oral surgery referral patterns given the anticipated change since the introduction by the General Dental Council of the specialty of surgical dentistry. Design Postal questionnaire.

Setting 400 GDPs in Greater Manchester.

Results $84 \%$ participation rate. $69 \%$ of dentists made a referral because of anticipated difficulty of surgery and $49 \%$ because of the complex nature of the patients' medical history. Practitioners who had undergone some oral surgery postgraduate training were more likely to undertake more surgery in their practices $(P<0.01)$ and to refer more patients for specialist care $(P<0.05)$. While female practitioners rated their own surgical confidence less highly than male practitioners $(P<0.001)$, and younger practitioners less than their older colleagues $(P<0.05)$, there was no significant difference in the number of referrals made.

Conclusion The most common reasons for referral were the anticipated difficulty of surgery and patient medical compromise. There was a wide variation between practitioners in the number of patients referred for specialist care. Postgraduate oral surgery training was identified as a factor contributing to this variation. Other practitioner variables, such as sex, experience and type of practice were not found to contribute.
\end{abstract}

$\mathrm{T}$ he referral system is a key feature of the British health service. Primary care practitioners act as the gate-keepers of expensive high-technology specialist care, using their professional skill in referring patients to the most appropriate specialist at the most appropriate time. While contributing to the relatively low cost of British health care, patients do have less autonomy than in many other countries where patients have direct access to specialists. ${ }^{1}$ If this is the case then it is important that the referral system in Britain is working effectively. Treatment as and when it is needed should be available to meet the patients' needs.

Prior to the reorganization of the UK National Health Service (NHS) in 1991 there was little information available about referral patterns of general practitioners to hospital services. However, some research studies had suggested that there was wide variation

\footnotetext{
${ }^{1}$ Lecturer in Oral Surgery, ${ }^{2}$ Postgraduate Student in Oral Surgery, ${ }^{3 *}$ Senior House Officer, ${ }^{4}$ Reader in Dental Statistics, Manchester University Dental Hospital, Higher Cambridge Street, Manchester M15 6FH

${ }^{\star}$ Present address: Charles Clifford Dental Hospital, Wellesley Road, Sheffield S10 2SZ

Correspondence to: Dr Paul Coulthard, Oral and Maxillofacial Surgery,

Manchester University Dental Hospital, Higher Cambridge Street,

Manchester M15 6FH

REFEREED PAPER

Received 14.05.99; accepted 02.11.99

(C) British Dental Journal 2000; 188: 142-145
}

among general medical practitioners in their rates of referral to hospital. This variation was interpreted by the Department of Health (1987) as indicating inefficient use of resources. Data systems have since been established to monitor referrals from general medical practitioners but such systems have not been established for dental practitioner referrals and still relatively little is known about these. Several studies have investigated dental practitioners' referral to orthodontic services ${ }^{2,3}$ but less is known about referral to oral surgery services. It is important to investigate these patterns because the decision to refer to specialist hospital care has social and economic implications, and because they provide information about the practitioners' preferences. The latter is particularly important at this time in the specialty of oral and maxillofacial surgery. It is anticipated that new forms of surgical practice will develop following the introduction by the General Dental Council of specialist lists for oral surgery and in particular for surgical dentistry. ${ }^{4}$ Hospital treatment is often less cost-effective than similar treatment in a primary care setting ${ }^{5}$ and as there is an increasing volume of oral surgery being undertaken, ${ }^{6}$ referral patterns may well be expected to change.

\section{Study objective}

To investigate the referral patterns of general dental practitioners to specialist oral surgery services in Greater Manchester.

\section{Methods}

A sample of 400 general dental practitioners was randomly selected from the Central Manchester NHS Trust database of Greater Manchester general dental practitioners. The study sample did not include any dental practitioners working completely independently from the National Health Service, as our initial source did not include these practitioners. The study design was two stage cross-sectional. Following piloting to check absence of ambiguity, a questionnaire was sent by post to each practitioner in the study. This study collected data in the form of dentists' opinions of their referral practice.

The questionnaire consisted of three sections:

\section{Section 1}

This section collected general information, including practice experience and type of practice. Information about postgraduate oral surgery training and level of confidence in performing oral surgery procedures was also requested.

Section 2

In this section, GDPs were asked to indicate their number of oral surgery referrals, reasons for referral and place of referral.

Section 3

GDPs were asked their opinion of the current referral system 
Table 1 Volume of oral surgery undertaken in general practice and number of oral surgery referrals to a specialist per month

\begin{tabular}{|c|c|c|c|c|c|c|}
\hline $\begin{array}{l}\text { Number of practice procedures } \\
\text { Number of GDP's } \\
\text { Percentage of GDPs }\end{array}$ & $\begin{array}{r}0-10 \\
271 \\
81\end{array}$ & $\begin{array}{r}11-20 \\
39 \\
12\end{array}$ & $\begin{array}{r}21-30 \\
14 \\
4\end{array}$ & $\begin{array}{r}31-40 \\
7 \\
2\end{array}$ & $\begin{array}{r}41-50 \\
1 \\
<1\end{array}$ & $\begin{array}{r}50 \\
4 \\
1\end{array}$ \\
\hline $\begin{array}{l}\text { Number of referrals } \\
\text { Number of GDP's } \\
\text { Percentage of GDPs }\end{array}$ & $\begin{array}{r}0-5 \\
252 \\
75\end{array}$ & $\begin{array}{r}6-10 \\
72 \\
21\end{array}$ & $\begin{array}{r}11-15 \\
11 \\
3\end{array}$ & $\begin{array}{r}16-20 \\
1 \\
<1\end{array}$ & & \\
\hline
\end{tabular}

including expectations of early patient consultation and desire to be more directly involved with the patient's consultation. This section is reported in Part 2 of this study.

\section{Results}

\section{Response rate}

From 400 questionnaires mailed to GDPs in Greater Manchester, 336 replies were received. This gave a participation rate of $84 \%$ and a sample representing just under half of the dental practitioners in Greater Manchester.

\section{Personal details}

Half $(48 \%)$ of the practitioners were in the 20-40 years' age range and half (52\%) were in the 41-70 years' age range. Almost half (49\%) were Manchester graduates, with the remainder distributed from the remainder of schools in the UK and the Irish Republic. Two hundred and thirty eight $(71 \%)$ of respondents were male and $98(29 \%)$ were female but any sex bias was reduced by the large sample size. A greater proportion of the younger age range group was female.

\section{Postgraduate oral surgery training}

Eighty (24\%) of the general dental practitioners had taken a short postgraduate course such as a Section 63 course and eight (2\%) had obtained a higher degree (MSc) in oral surgery. Thirty four (10\%) had worked as a house officer or senior house officer in oral surgery and $19(6 \%)$ as a clinical assistant. Thirty four $(10 \%)$ had received some training as part of vocational training. One hundred and ninety three (57\%) practitioners had not received any postgraduate oral surgery training.

Type of practice and oral surgery undertaken in general practice Most $(80 \%)$ practitioners worked in multi-handed practices, with only $67(20 \%)$ working alone. The vast majority of practitioners $(81 \%)$ reported carrying out few (between 0 and 10 ) oral surgery procedures per month. However, 4 (1\%) practitioners carried out more than 50 procedures per month. The volume of oral surgery undertaken by GDPs is shown in Table 1. Practitioners who had undergone some postgraduate oral surgery training were more likely to carry out oral surgery in practice than those who had not (chi-squared $=10.0 ; 1$ degree of freedom; $P=0.002$ ). There was no significant difference in the number of surgical procedures carried out by practitioners according to sex or to the number of years spent in practice.

\section{GDP confidence in performing oral surgery procedures}

General practitioners were asked to rate their level of confidence in performing oral surgery in practice from 1 (not confident) to 4 (very confident). Thirty nine (12\%) gave a confidence score of 1 and $29(9 \%)$ a score of 4 with the remainder giving scores of 2 or 3. Male practitioners were found to rate their confidence more highly than female practitioners (chi-squared linear trend $=14.0 ; 1$ degree of freedom; $P<0.001$ ). Practitioners who had spent more years in general practice were more likely to give higher confidence

\section{Table 2 Reasons for GDP referral to specialist oral} surgery services

Reason giving reason (\%)

Anticipated difficulty of surgery

Complicated medical history

Need of second opinion

Preference not to undertake surgical procedures

Lack of appropriate facilities or staff

$106(32)$

$98(29)$

Emergency management of pain/swelling/haemorrhage

score than those less experienced (chi-squared linear trend = 14.9; 1 degree of freedom; $P=0.03$ ) as were those who had undergone some form of postgraduate oral surgery training (chi-squared linear trend $=20.3$; 1 degree of freedom; $P<0.001$ ). Postgraduate oral surgery training which included practical hands-on operative work was a more powerful predictor of confidence than more limited postgraduate experience (chi-squared linear trend $=8.0 ; 1$ degree of freedom $P=0.005)$.

\section{Number of oral surgery patients referred}

The majority of practitioners $(75 \%)$ reported referring between 0 and 5 patients per month. One $(0.3 \%)$ practitioner gave a referral score of between 16 and 20 patients per month. The number of patients referred by GDPs is shown in Table 1. Practitioners who had undergone some postgraduate oral surgery training were more likely to refer more patients than those who had not (chi-squared $=7.5 ; 1$ degree of freedom; $P=0.006$ ). Postgraduate oral surgery training which included practical hands-on operative work was not a more powerful predictor of the number of patients referred than more limited postgraduate experience (chi-squared linear trend $=0.53 ; 1$ degree of freedom $P=0.47$ ). There was no significant difference in the number of patients referred by practitioners according to sex or to the number of years spent in practice or the type of practice.

\section{Reasons for making an oral surgery referral}

Six potential reasons for referral of a patient to a specialist oral surgery service were listed in the questionnaire. Respondents were invited to state which of these were their reasons for referral. The results are shown in Table 2. The commonest two reasons for referral were the anticipated difficulty of surgery and the complicated nature of the medical history. Respondents were not specifically asked to specify further reasons, although the opportunity for additional comment was present. Some respondents (12\%) complained that their main reason for referring patients for oral surgery treatment was that the NHS fee scale did not adequately reimburse for this type of treatment in the General Dental Service.

\section{Place of referral}

Ninety three per cent of practitioners said that they would refer more than $75 \%$ of their patients to the hospital oral and maxillofa- 
cial surgery service with few practitioners referring to a community or practice specialist service.

\section{Factors influencing choice of oral surgery specialist service}

The most important factors in choosing an oral surgery service were reported to be the length of the waiting list for consultation and treatment and personal knowledge of the surgeon, both influencing $57 \%$ of dentists (Table 3 ). Ease of access for the patient and the perceived standard of treatment offered by the specialist was an influencing factor for $52 \%$. One third (31\%) of dentists were influenced by the ease of making the consultation appointment in choosing their service provider and $27 \%$ would choose according to the type of surgical treatment required. The standard of the specialist's report returned to the practitioner was also an influencing factor for $14 \%$.

\section{Table 3 Factors influencing choice of oral surgery treatment provider (total number of dentists $=336$ )}

\begin{tabular}{lr}
\hline Factor & Number $(\%)$ \\
\hline & \\
Length of waiting list & $190(57)$ \\
Personal knowledge of surgeon & $190(56)$ \\
Ease of access for the patient & $174(52)$ \\
Standard of treatment & $173(52)$ \\
Ease of making consultation appointment & $105(31)$ \\
Type of surgery required & $89(27)$ \\
Standard of surgeon's report & $48(14)$ \\
\hline
\end{tabular}

\section{Discussion}

The study area and sample

The study area was well suited to a study of this nature as it has a number of oral and maxillofacial surgery hospital departments and also community clinics and general dental practices offering an oral surgery service. However the study did not take into account private referrals or referrals from general practitioners working independently from the NHS.

\section{General dental practice oral surgery and referrals}

Male practitioners reported significantly more confidence in performing their own oral surgery than female practitioners. However, female practitioners carried out no less surgery in practice and referred no more patients to a specialist service than male practitioners confirming that while they expressed less confidence, they were not less capable. Practitioners who had undergone some postgraduate oral surgery training also reported more surgical confidence, particularly those having hands-on operating experience. These practitioners carried out more surgery in practice themselves but also referred more patients to specialist facilities. While there are no simple indicators that referral pattern may reflect differences in knowledge, other authors have suggested that background, training, and specialist interests might account for at least some of the variation. Forsyth and Logan showed that medical practitioners who held clinical assistantships in hospitals had rates of referral which were much the same as their colleagues, and that degrees and diplomas held bore relationship to referral behaviour. ${ }^{7}$ However a later study by Reynolds et al. showed that doctors with particular experience in otorhinolarynology and opthalmology had higher rates of referral to these specialties. ${ }^{8}$

While Matthews has reported that new graduates may carry out more oral surgery as a possible reflection of improved surgical teaching and confidence in performing minor oral surgery, ${ }^{9}$ more experienced practitioners were found to carry out their own oral surgery with significantly more confidence than those who had spent less time in general practice. However, while practitioners who had spent longer in practice reported more surgical confidence, they referred no fewer patients than those less experienced who had less confidence. A similar finding has been observed in medical practice where, contrary to popular belief, more experienced doctors made no less use of hospital services than their younger colleagues. ${ }^{10}$ Single handed practitioners referred no more patients than those working in multihanded practices. This has also been shown to be the case in several studies for medical practitioners. ${ }^{7,10,11}$

A wide variation between practitioners in the number of patients referred per month was observed. While no attempt was made to calculate referral rates by relating the number of referrals to the total number of patients under the care of each dentist, similar variation has been described in orthodontic referrals as well as in studies investigating referral from general medical practice to secondary care providers. ${ }^{2,10}$ Variation in referral rates may imply that one practitioner is referring inappropriately or conversely that another is denying the benefit of specialist care to his or her patients. However, care must be taken in drawing such conclusions even when taking into account the number of patients on a dentist's list. It could be that a practitioner has a large number of patients registered but is gradually reducing his workload and his list size bears little relation to the number of patients he or she sees. Alternatively, one practitioner may see many more casual patients than another and this may skew the referral rate. Similarly, practices differ in age structure. A particular practice may provide care for a large number of college students and this may increase the number of referrals for third molar surgery.

Some variation in referral rates can be expected because of random variation in the presentation of patients requiring referral, that is, because of chance. Moore and Roland have described a mathematical model to calculate the amount of variation in rates of referral that is likely to be caused by chance alone. ${ }^{12}$ However, this model assumes referral from medical practices of average list size of 2,000 patients per doctor and to medical specialties in larger numbers than occur to dental specialties. This model may not therefore be transferable to dental referrals.

\section{Reasons for referral}

The most common reasons for the dentists in this study to refer a patient to a specialist oral surgery service were the anticipated difficulty of performing the surgery and the complicated nature of the medical history. The same reasons have been reported by Absi who suggested that $70 \%$ of their medically compromised study patients had no special requirements other than those available in the general dental service (GDS). ${ }^{13}$ An alternative view has been put by Sadler who advised that despite the advantage of cost-effectiveness of oral surgery treatment in primary rather than secondary care, some patients with medical compromise would be better managed by the hospital service. ${ }^{14} \mathrm{Absi}^{13}$ reasoned that a large proportion of patients were unnecessarily receiving treatment in hospital because most were in fact treated by very junior staff. However, patients were under the care of consultants and the treatment plan for management is likely to have involved senior staff. Perhaps more medically compromised patients could only be managed in the primary care setting if specialist advice were more readily accessible. Telemedicine, as described in Part 2 of this study, may offer a feasible method for the practitioner to improve communication with the specialist.

Other reasons included the need for a second opinion, dislike of undertaking oral surgery or the lack of facilities or appropriately trained staff. Some respondents offered that a reason for referral was their perceived inadequacy of the NHS fee to undertake oral surgery in practice. Another problem raised in other studies is the anomaly that patients have to pay toward the cost of treatment in the GDS when hospital treatment is free. ${ }^{14,15}$

Only a small number (11\%) of dentists referred patients for emergency relief of pain, swelling or haemorrhage. This suggests 
that despite an almost twofold increase in the provision of emergency dental care in the GDS since $1989,{ }^{15}$ most dentists were operating their own emergency service successfully.

The understanding of oral surgery referral rates is confounded because some general dental practitioners are in fact able to provide dentoalveolar surgery treatment themselves in their practices. Indeed in this study four (1\%) practitioners carried out more than 50 oral surgery procedures per month. Personal preference, as already mentioned, is another factor. All dentists are expected to be competent on graduation to undertake oral surgery procedures commonly undertaken in general dental practice ${ }^{16}$ but a practitioner may exercise his clinical freedom to pursue a specialist interest or limit his oral surgery practice.

\section{Choice of specialist provider}

In the past, British General Medical Practitioners (GMPs) have been free to refer their patients to any hospital or consultant clinic in the country and the same strategy was followed by General Dental Practitioners (GDPs). However, with the introduction of the internal market in healthcare, following the 1990 NHS and Community Care Act, there have been some limitations to this freedom. Irrespective of these, there are practical limitations to referral. ${ }^{1}$ The most obvious practical limitation is the distance that a patient may have to travel to seek specialist care, and certainly most GMP referrals go the hospital nearest to the practice. In this study most referrals were to the hospital service rather than a specialist service in the primary care setting of the practice or community clinic. As the hospital service has traditionally been the only service available, this is not unexpected, but with the advent of surgical dentistry, change may be anticipated. Other factors are also known to influence referral patterns. These include transport available to the patient, the length of the waiting list for consultation and treatment, the preference of the referrer for a particular consultant to care for his patient, technical facilities available and the perceived standard of treatment. In this study the most important factors in choosing an oral surgery specialist provider were the length of the waiting list for consultation and treatment, and personal knowledge of the surgeon. Dentists must be provided with accurate and up-todate information about waiting times if they are to make informed decisions. Preferred specialist has been shown to be an important factor for practitioners in other studies. In one study, 93\% of medical practitioner referrals went to a named consultant. ${ }^{17}$

The standard of care provided by the specialist unit was also important to the dentists in this study. However the perceived standard of care and actual standard of care may of course be different. This emphasises the importance of progression toward the routine measurement of health outcomes and dissemination of these to the primary care practitioners.

\section{Conclusions}

The most common reasons for referral were the anticipated difficulty of surgery and patient medical compromise. There was a wide variation between practitioners in the number of patient referred for specialist care. Postgraduate oral surgery training was identified as a factor contributing to this variation. Other factors, such as sex, experience and type of practice were not found to contribute.

This study has focused on the issue of general dental practitioner referral patterns to specialist oral surgery services. It must be remembered that this is only one facet of the interface between primary and secondary care and care must be taken in interpreting the results. They do not tell us about the quality of care and health outcomes, although this study indicates that practitioners wish to have information about these. Higher referrers are not necessarily wasting specialist resources and low referrers denying care to their patients. Therefore while politicians and health service managers may assume reducing variation in referrals will reduce costs, this may not necessarily be the case as it may involve increasing referrals from low referrers as well as reducing referral by high referrers.

The authors thank all the Greater Manchester dental practitioners who took the time to complete the questionnaire.

1 Coulter A. The interface between primary and secondary care. In Roland M and Coulter A. (eds) Hospital referrals. pp 1-14 Oxford: Oxford General Practice Series, 1992.

2 O’Brien K, McComb J L, Fox N, Bearn D and Wright J. Do dentists refer orthodontic patients inappropiately? Br Dent J 1996; 181: 132-136.

3 Bowden D, Pender N, Hussain J, Morris T and Russell J. An attempt to influence the referral of orthodontic patients to hospital orthodontic departments. Health Trends 1996; 28: 67-70.

4 General Dental Council. Specialist Dental Lists. London, April 1998

5 Flasher H A. Wisdom tooth waiting lists. Br Dent J 1990; 168: 50.

6 Thomas D, Walker R, Smith A and Shepherd J. The provision of oral surgery services in England and Wales 1984-1991. Br Dent J 1994; 176: 215-219.

7 Forsyth G, Logan R F L. Gateway or dividing line? A study of hospital outpatients in the 1960s. Oxford: Oxford University Press, 1968.

8 Reynolds G A, Chitnis J G and Roland M O. General practitioner outpatient referrals: do good doctors refer more patients to hospital? B Med J 1991; 302: 1250-1251.

9 Matthews R W, Porter S R, Scully C, Levers B G H. Confidence levels of new UK dental graduates. J Dent Res 1991; 70: 726.

10 Wikin D and Smith A G. Variation in general practitioners' referral rates to consultants. J R College Gen Prac 1987; 37: 350-353.

11 Scott R, Gilmore M. Studies of hospital outpatients services: 1 In $\mathrm{G}$ McLachlan (ed) The Edinburgh Hospitals. Problems and Progress in Medical Care. pp3-41 Oxford: Oxford University Press, 1966.

12 Moore A T and Roland M O. How much variation in referral rates among general practitioners is due to chance? Br Med J 1989; 302: 1250-1252.

13 Absi E G, Satterthwaite J, Shepherd J P, Thomas D W. The appropriateness of referral of medically compromised dental patients to hospital. Br J Oral Maxillofac Surg 1997; 35: 133-136.

14 Sadler A, Davidson M, Houpis C, Watt-Smith S. Specialist practice for minor oral surgery: a comparative audit of third molar surgery. Br Dent J 1993; 174: 273-277.

15 Crawford A N. Recalled dental attendance; its cost to the NHS. Br Dent J 1994; 176: 363-364.

16 General Dental Council. The first five years. The undergraduate dental curriculum. 1997.

17 Bradlow J, Coulter A, Brookes P. Patterns of referral. Health Services Research Unit, Oxford, 1992. 